\title{
A bibliometric analysis of the intelligent transportation systems research based on science mapping
}

\author{
M.J. Cobo, F. Chiclana, A. Collop, J. de Oña and E. Herrera-Viedma
}

\begin{abstract}
In this paper we highlight the conceptual structure of the Intelligent Transportation Systems (ITS) research field in the period 1992-2011. To do that, an automatic approach for detecting and visualizing hidden themes and their evolution across a consecutive span of years is applied. This automatic approach, based on co-word analysis, combines performance analysis and science mapping. To show the conceptual evolution of ITS, three consecutive periods have been defined: 19922001, 2002-2006, 2007-2011. We have identified that the ITS research has been focused on six main thematic areas: VEHICLE-AND-ROAD-TRACKING, DRIVER-BEHAVIORAND-SAFETY, SCENARIOS-SIMULATION, TRAFFIC-FLOWAND-TRAFFIC-MANAGEMENT, VEHICLE-CONTROL and VEHICLE-NAVIGATION.
\end{abstract}

Index Terms-Intelligent Transportation Systems, Science Mapping Analysis, Co-word Analysis, H-index.

\section{INTRODUCTION}

According to the IEEE Intelligent Transportation Systems (ITS) Society (http://sites.ieee.org/itss/), ITS can be described as systems that utilize "synergistic technologies and systems engineering concepts to develop and improve transportation systems of all kinds".

Science Mapping Analysis [1], [2] is a powerful bibliometric technique that allows the study of the conceptual structure of a particular research field. It can be described as a spatial representation of how disciplines, fields, specialities, and individual documents or authors are related to one another. It is focused on monitoring a scientific field and delimiting research areas to determine its structure and its evolution.

In the ITS research community we find few bibliometric studies. Only IEEE Trans. ITS journal has shown interest in developing a bibliometric analysis of its particular output [3]-[6]. Therefore, a complete ITS science mapping study is still in need. In this paper we present a complete longitudinal Science Mapping Analysis where the whole ITS research field is analyzed and its conceptual evolution discovered. We use the research documents related with ITS during the period 19922011 published in the most important and influential journals in the field (J. of Int. Trans. Sys., ITS Journal, IET Int. Trans.

M.J. Cobo is with Dept. Computer Science, University of Cádiz, Spain (e-mail: manueljesus.cobo@uca.es)

F. Chiclana and A. Collop are with School of Computer Science and Informatics, Faculty of Technology, De Montfort University, UK. (email: \{chiclana,acollop\}@dmu.ac.uk)

J. de Oña is with TRYSE Research Group. Dept. of Civil Engineering, University of Granada, Spain. (email: jdona@ugr.es)

E. Herrera-Viedma is with the Dept. Computer Science and A.I. (CITICUGR), University of Granada, Spain (e-mail: viedma@decsai.ugr.es).
Sys. and IEEE Trans. ITS.). Furthermore, we complete the dataset by selecting others documents containing the keyword "Intelligent Transportation". The Science Mapping Analysis is performed using the software tool SciMAT [7], [8].

The rest of the paper is organized as follow: Section II shows the approach and software used in the Science Mapping Analysis. Section III presents the results of our analysis. Finally, in Section IV some conclusions are remarked.

\section{Science Mapping Analysis: Methodology And SOFTWARE TOOL}

In bibliometrics, there are two main procedures to explore a research field: performance analysis and science mapping [9]. The former is focused on the citation based impact of the scientific production and the latter is focused on the discovering of the conceptual structure of the scientific production. In [7] we define a bibliometric approach that combines both approaches. Co-word analysis is used in a longitudinal framework which allows us to analyze and track the evolution of a research field throughout consecutive time periods [10].

Our bibliometric methodology establishes four phases to analyse a research field [7]:

1) Research themes detection. To do so, an equivalence index [11] normalized bibliometric co-word network of keywords co-occurrence is built [12]. This is followed by a clustering of keywords to topics/themes using the simple centers algorithm.

2) Low dimensional space layout of research themes. This is achieved by plotting research themes using twodimensional strategic diagrams based on their centrality and density rank values [11]. Centrality measures the degree of interaction of a network with other networks and it can be defined as: $c=10 * \sum e_{k h}$, with $k$ a keyword belonging to the theme and $h$ a keyword belonging to other themes. Density measures the internal strength of the network and it can be defined as: $d=100 \frac{\sum e_{i j}}{w}$, with $i$ and $j$ keywords belonging to the theme and $w$ the number of keywords in the theme. Thus, the research themes can be classified into four groups [7]: a) motorthemes, b) basic and transversal themes, c) emerging or declining themes, and d) highly developed and isolated themes.

3) Discovery of thematic areas. The evolution of the research themes is analyzed to detect the main general evolution areas of the research field, their origins, as well 
as their interrelationships. To do that, an evolution map is built. The inclusion index is used to detect conceptual nexus between research themes of different periods.

4) Performance analysis. In this phase, the relative contribution of research themes and thematic areas to the whole research field is measured (quantitatively and qualitatively), which is used to establish the most prominent, productive and highest-impact subfields. Some bibliometric indicators used are: number of published documents, number of received citations, and h-index [13].

Finally, the open-source software SciMAT [7], [8] is used.

\section{CONCEPTUAL STRUCTURE OF ITS RESEARCH FIELD}

We develop our analysis of ITS field by using the research documents published in the main journals of the field (J. of Int. Trans. Sys., ITS Journal, IET Int. Trans. Sys. and IEEE Trans. ITS.). We complete the corpus with those documents containing the keyword "Intelligent Transportation". Then we retrieve the necessary data from the ISI Web of Science (ISIWoS) using the following query: TS=("INTELLIGENT TRANSPORT*") OR SO=("Journal of Intelligent Transportation Systems" OR "ITS Journal” OR "IET Intelligent Transport Systems" OR "IEEE TRANSACTIONS ON INTELLIGENT TRANSPORTATION SYSTEMS”). The query is divided in two parts: i) documents related with the term "Intelligent transport" and its variations, and ii) documents published in the main journals in the field. We retrieve a total of 2045 documents (articles, letters, notes and reviews) from 1992 to 2011. In this study the citations to the documents are also used; for this reason, citation counts up to September 11th 2012 were considered.

Once the data was downloaded, we import it into SciMAT [8]. A de-duplicating process was applied over the keywords (as unit of analysis we jointly use the author's keywords and the Keywords Plus) in order to group those words representing the same concept. Furthermore, because some documents did not contain any keywords, a manual addition of descriptive keywords matching title words with keywords present in the knowledge base was done for completeness purposes. Finally, some keywords meaningless in this context such as stop words, or words with a very broad and general meaning, such as Intelligent Transportation Systems, were removed.

To develop our study the whole time period (1992-2011) is divided into three consecutive periods of time: 19922001, 2002-2006 and 2007-2011, with 793, 1565 and 3249 keywords, respectively.

In what follows we identify the ITS research themes for each period and analyze the thematic evolution of the ITS field.

\section{A. Identifying the ITS research themes}

In order to analyze the most highlighted themes of the ITS field for each period several strategic diagrams are shown. In they, the sphere size is proportional to the number of published documents associated with each research theme. Additionally, the number of citations achieved by each theme is shown in parenthesis.

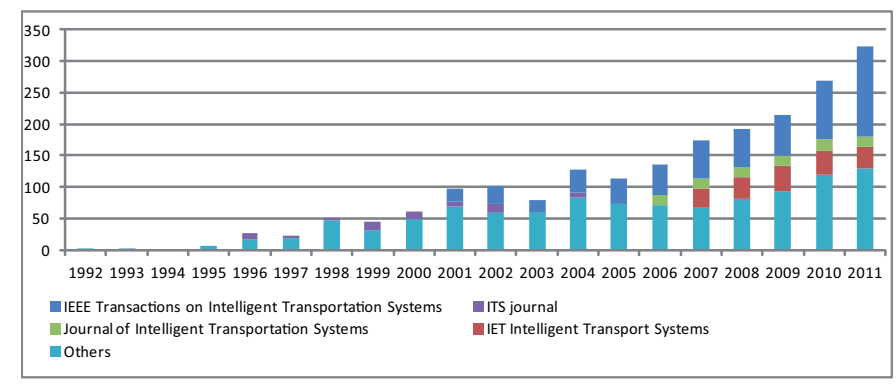

Fig. 1. ISIWoS ITS research documents published from 1992 to 2011.

During the period 1992-2001 (Fig. 2.a and Table I), the ITS research field was focused in three main themes (see Fig. 2.a): i) VEHICLES, dedicated to the vehicle surveillance, traffic and incidents detection; ii) TRAVELER-INFORMATION-SYSTEM, focused on to assist and guide the traveler in the choice of route, and also it is related with the management of traffic; iii) SHORTEST-PATH, centered on to find the best path, both in time and distance, in a traffic network.

TABLE I

PERFORMANCE MEASURES FOR THE THEMES (1992-2001).

\begin{tabular}{|l|r|r|r|}
\hline Theme name & Number of documents & Number of citations & h-index \\
\hline VEHICLES & 49 & 303 & 9 \\
TRAVELER-INFORMATION-SYSTEMS & 24 & 223 & 7 \\
SHORTEST-PATH & 21 & 214 & 6 \\
NEURAL-NETWORKS & 15 & 213 & 5 \\
CDMA & 10 & 220 & 7 \\
SPEED & 8 & 22 & 2 \\
\hline
\end{tabular}

From 2002 to 2006, we obtain the strategic diagrams shown in Fig. 2.b and bibliometric indicators shown in Table II:

- The number of themes is increased.

- The majority of the basic and transversal themes are focused on vehicles, safety and traffic management.

- The theme TRACKING emerges as an important motor theme and it achieves the highest impact index.

- The theme BEHAVIOR appears as motor theme with high density and centrality values. It is focused on the behavior of the drivers and how they choose their travel routes.

- The research themes TRAVELER-INFORMATIONSYSTEMS and NEURAL-NETWORK related with traffic management, which previously were considered trend and emergent themes respectively, have been consolidated as basic theme.

- DECISION-MAKING, focused on safety and risk management, appears as a new basic and transversal theme.

- The highly developed and isolated themes are mainly focused on themes related with vehicle navigation such as: GPS, VEHICLE-ROUTING.

From 2007 to 2011, we obtain the strategic diagrams shown in Fig. 2.c and bibliometric indicators shown in Table III:

- There is a higher number of motor themes than in the previous period. Indeed, there is an adequate number of emerging themes, which indicates that the ITS research field is still developing and growing.

- The ITS research field increments its interest in themes related with vehicle tracking, such as: TRACKING, CLASSIFICATION and RECOGNITION. 


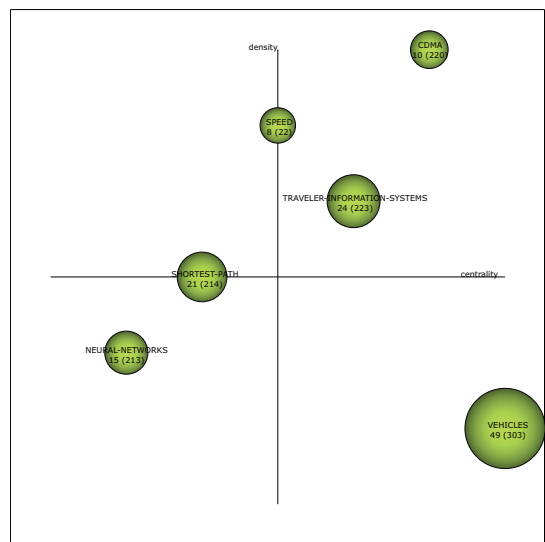

(a) Period 1992-2001.

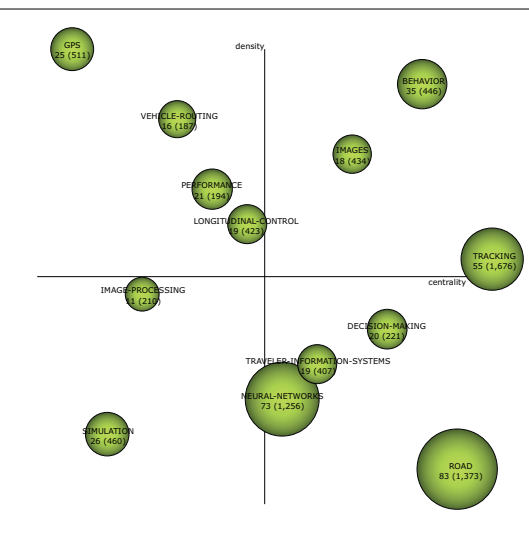

(b) Period 2002-2006.

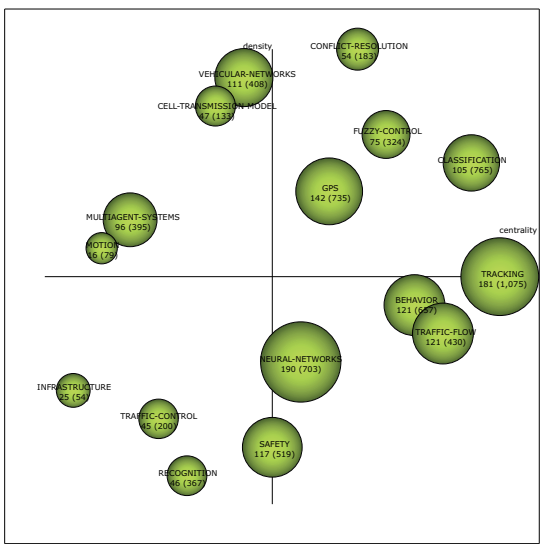

(c) Period 2007-2011.

Fig. 2. Strategic diagrams

TABLE II

Performance MEASURES FOR THE THEMES (2002-2006).

\begin{tabular}{|l|r|r|r|}
\hline Theme name & Number of documents & Number of citations & h-index \\
\hline ROAD & 83 & 1,373 & 21 \\
NEURAL-NETWORKS & 73 & 1,256 & 20 \\
TRACKING & 55 & 1,676 & 25 \\
BEHAVIOR & 35 & 446 & 11 \\
SIMULATION & 26 & 460 & 11 \\
GPS & 25 & 511 & 15 \\
PERFORMANCE & 21 & 194 & 7 \\
DECISION-MAKING & 20 & 221 & 6 \\
LONGITUDINAL-CONTROL & 19 & 423 & 12 \\
TRAVELER-INFORMATION-SYSTEMS & 19 & 407 & 10 \\
IMAGES & 18 & 434 & 12 \\
VEHICLE-ROUTING & 16 & 187 & 7 \\
IMAGE-PROCESSING & 11 & 210 & 6 \\
\hline
\end{tabular}

- The themes NEURAL-NETWORK and TRACKING consolidate as basic and transversal themes.

- BEHAVIOR develops into an important basic and transversal theme.

- The theme GPS gains strong interest and becomes one of the major motor themes.

- FUZZY-CONTROL, related with vehicle control, emerges as a motor theme.

- The themes TRAFFIC-CONTROL and RECOGNITION appears as emerging themes and they obtain a great interest

- The highest density value is achieved by the motor theme CONFLICT-RESOLUTION related with air traffic control.

TABLE III

Performance MeAsures For the themes (2007-2011).

\begin{tabular}{|l|r|r|r|}
\hline Theme name & Number of documents & Number of citations & h-index \\
\hline NEURAL-NETWORKS & 190 & 703 & 11 \\
TRACKING & 181 & 1,075 & 17 \\
GPS & 142 & 735 & 12 \\
BEHAVIOR & 121 & 657 & 14 \\
TRAFFIC-FLOW & 121 & 430 & 11 \\
SAFETY & 117 & 519 & 12 \\
VEHICULAR-NETWORKS & 111 & 408 & 12 \\
CLASSIFICATION & 105 & 765 & 15 \\
MULTIAGENT-SYSTEMS & 96 & 395 & 11 \\
FUZZY-CONTROL & 75 & 324 & 10 \\
CONFLICT-RESOLUTION & 54 & 183 & 7 \\
CELL-TRANSMISSION-MODEL & 47 & 133 & 7 \\
RECOGNITION & 46 & 367 & 11 \\
TRAFFIC-CONTROL & 45 & 200 & 8 \\
INFRASTRUCTURE & 25 & 54 & 4 \\
MOTION & 16 & 79 & 5 \\
\hline
\end{tabular}

\section{B. Thematic Evolution of the ITS Field}

An analysis of the themes detected in each one of the three times periods evaluated, their keywords compositions and their evolution across the consecutive defined periods of time, leads to the detection of the following six main thematic areas (Fig. 3): i) VEHICLE-AND-ROAD-TRACKING, ii) DRIVER-BEHAVIOR-AND-SAFETY, iii) SCENARIOSSIMULATION, iv) TRAFFIC-FLOW-AND-TRAFFICMANAGEMENT, v) VEHICLE-CONTROL, vi) VEHICLENAVIGATION.

The solid lines mean a thematic nexus: both themes have the same name, or the name of one of them is part of the other theme. A dotted line means that the linked themes share keywords different to the name of the themes. The thickness of the edge is proportional to the inclusion index, and the sphere size is proportional to the number of published documents in each theme. The different colour-shadows group the themes that belong to the same thematic area.

TABLE IV

PERFormanCE MEASURES For THE DETECTED THEMATIC AREAS.

\begin{tabular}{|l|r|r|r|}
\hline Thematic area & Number of documents & Number of citations & h-index \\
\hline VEHICLE-AND-ROAD-TRACKING & 473 & 4604 & 34 \\
TRAFFIC-FLOW-AND-TRAFFIC-MANAGEMENT & 409 & 3104 & 27 \\
DRIVER-BEHAVIOR-AND-SAFETY & 320 & 1891 & 21 \\
VEHICLE-NAVIGATION & 202 & 1617 & 22 \\
SCENARIOS-SIMULATION & 141 & 1076 & 17 \\
VEHICLE-CONTROL & 115 & 1081 & 20 \\
\hline
\end{tabular}

Analyzing Fig. 3 and Table IV several conclusion regarding different structural and performance aspects are noted:

1) Regarding the thematic composition it was found:

- The thematic areas VEHICLE-AND-ROADTRACKING and TRAFFIC-FLOW-AND-TRAFFICMANAGEMENT are mainly composed by motor and basic themes. The former includes in its origin just one basic theme, and it becomes the thematic area with most number of themes. The latter counts in its origin one motor theme and one emergence theme and both evolve as basic and/or motor themes.

- The thematic area VEHICLE-NAVIGATION starts as an isolated theme and it develops into one of the most important motor themes in the last period. 


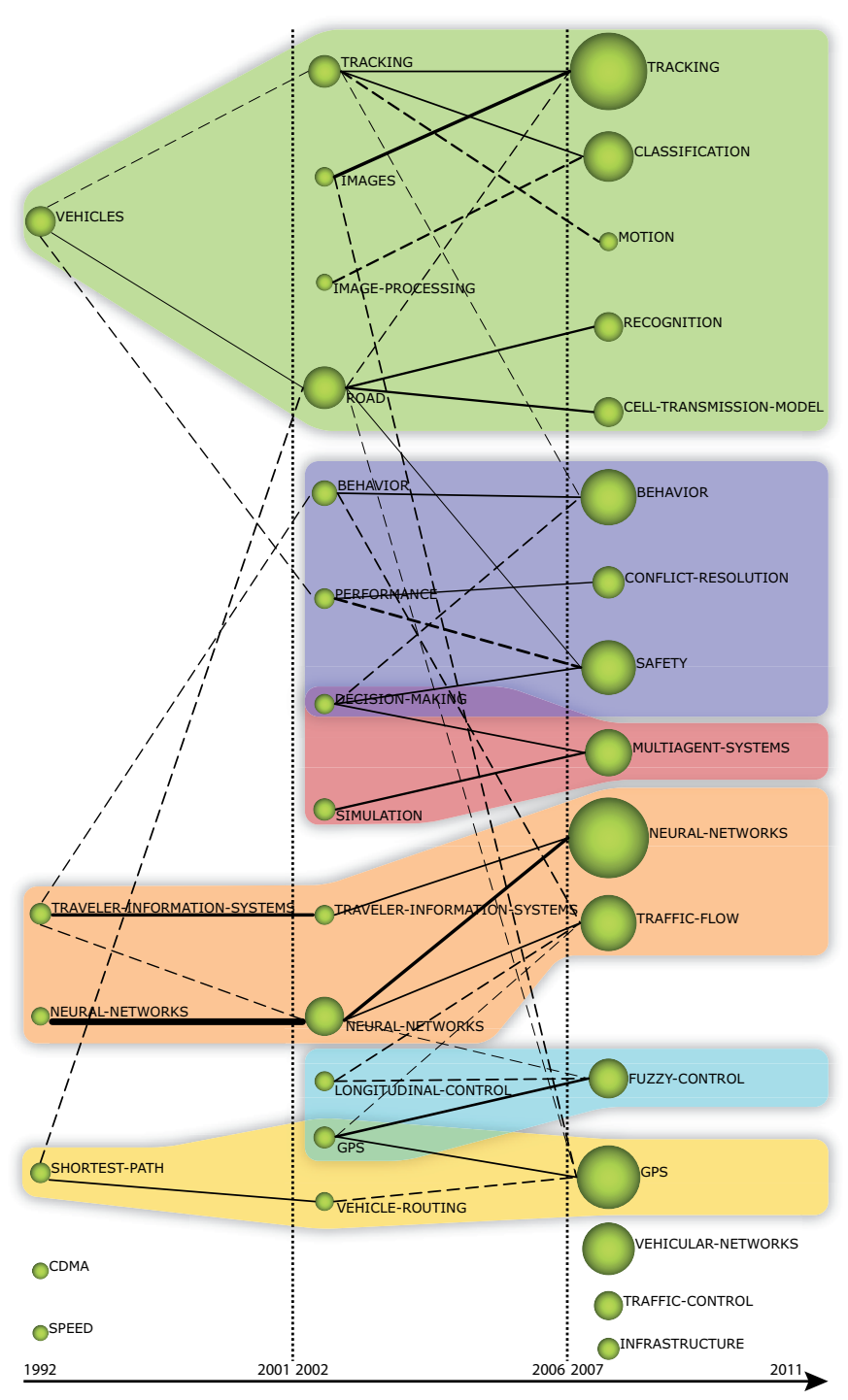

Fig. 3. Thematic evolution of the ITS research field (1992-2011).

- DRIVER-BEHAVIOR-AND-SAFETY arises comprised by motor and basic themes and one isolated theme. This thematic area evolves positively and their themes become important basic themes.

- SCENARIOS-SIMULATION is mainly composed by highly developed but isolated themes.

- VEHICLE-CONTROL starts from two isolated themes and it converges into an important motor theme.

- The theme DECISION-MAKING is shared by two thematic areas: DRIVER-BEHAVIOR-ANDSAFETY and SCENARIOS-SIMULATION. Similarly, the theme GPS belongs to two thematic areas: GPS and VEHICLE-CONTROL.

2) Regarding the structural evolution, the following should be pointed out:

- The ITS field presents great cohesion, due to the fact that the majority of detected themes are grouped under a thematic area and originate from a theme identified in a previous period. Furthermore, most of the evolutions are part of a thematic nexus.

- Three thematic areas start in the first period: VEHICLE-AND-ROAD-TRACKING, TRAFFICFLOW-AND-TRAFFIC-MANAGEMENT and VEHICLE-NAVIGATION. The second period also includes the start of the following three themes: DRIVER-BEHAVIOR-AND-SAFETY, SCENARIOSSIMULATION and VEHICLE-CONTROL.

- We find some very recent themes (for example, VEHICULAR-NETWORKS and TRAFFICCONTROL) that could not be identified with any thematic. They could be considered as the beginning of a new thematic area.

- There are no gaps in the evolution of the majority of thematic areas.

- The thematic areas VEHICLE-AND-ROADTRACKING and TRAFFIC-FLOW-AND-TRAFFIC$M A N A G E M E N T$ present a growing pattern. On the other hand, SCENARIOS-SIMULATION, VEHICLENAVIGATION and VEHICLE-CONTROL shrink in the last period.

- We should point out that although a shrinking pattern is identified for VEHICLE-NAVIGATION and VEHICLE-CONTROL, they evolve as important thematic areas in the last period, merging together into one motor theme. In fact, VEHICLE-CONTROL appears as a bifurcation of GPS.

3) Regarding the performance and impact indicators it was found that:

- The thematic area VEHICLE-AND-ROADTRACKING is the most important in number of document, citations and with the highest h-index. Also, TRAFFIC-FLOW-AND-TRAFFICMANAGEMENT reaches good bibliometric indicators as it is shown in Table IV.

- All thematic areas show a growing pattern in the number of document. Specially significant is the case of VEHICLE-NAVIGATION and VEHICLECONTROL, which despite reducing the number of themes across the periods, they increase in number of documents.

- Only TRAFFIC-FLOW-AND-TRAFFICMANAGEMENT presents a descending pattern in both number of citations received and $\mathrm{h}$ index. This suggests that although the research community is still interested in this thematic (it gets an adequate number of documents in the last period) the publication impact seems to be decreasing.

Once the thematic areas have been analyzed according to their structural, thematic and performance aspects, we provide a more detailed analysis of the conceptual evolution of each thematic area through the different time spans. In what follows, we describe how each thematic area evolves.

The thematic area VEHICLE-AND-ROAD-TRACKING starts in the period 1992-2001. In those years the thematic was not well developed being a transversal topic. In the next period 
(2002-2006), the thematic broadened covering topics related with the extraction of the visual information present in the streets and roads [14], detection and recognition of different object [15], [16], road detection [17], vehicle tracking [18], etc. Finally, in the last period the thematic focused on object detection in complex situations, such as: lane curvature [19] or night vision [20]; as well as in advance problems such as: prediction of drivers intentions [21] and object detection in real-time [22].

DRIVER-BEHAVIOR-AND-SAFETY was mainly related with the improvement of the safety of the driver in the vehicle. To do that, techniques such as the driver's stress level detection [23], speed adaptation systems [24] and driver's behaviour control [25] were developed. This thematic area also covers topic such as the behaviour of drivers in traffic congestion [26].

SCENARIOS-SIMULATION starts in the period 2002-2006 with a focus on the simulation of different aspects such as, motorway network and traffic flow model [27]. Finally, in the period 2007-2001 the thematic area focused on the same topics, but using intelligent agents systems to develop simulations [28].

In the early years of the thematic area TRAFFIC-FLOWAND-TRAFFIC-MANAGEMENT we locate the firsts papers describing traveler information systems [29] and their use to reduce travel time and traffic congestion [30]. In the next period (2002-2006), the thematic area goes further in the development of advance traveler information system [31]. Finally, in the last period it evolves to focus on the prediction of traffic flow [32] in real time environments [33].

In the period 2002-2006 the thematic area VEHICLECONTROL focused on several issues related to autonomous vehicle control [34], [35]. In the last period, 2007-2011, several advance developments on specific topics of autonomous vehicle control were carried out: lane change [36], unintended lane departure [37], etc.

In the period 1992-2001, the thematic area VEHICLENAVIGATION focused on solving the shortest route problem, both in distance [38] and time [39]. In the next period the thematic area developed and it was divided in two main topics: GPS [40] and vehicle routing in real time [41]. Finally, in the period 2007-2011, the thematic area focused on the topic GPS, as well as in improving its accuracy, availability, and continuity of service [42].

\section{CONCLUding Remarks}

In this paper we have analyzed the conceptual structure of the Intelligent Transportation Systems (ITS) research area by means of science mapping analysis and co-word networks. Three consecutive period of time have been studied: 1992 2001, 2002-2006 and 2007-2011. We have considered the research documents developed in the following ITS journals: J. of Int. Trans. Sys., ITS Journal, IET Int. Trans. Sys. and IEEE Trans. ITS. Moreover, we completed the dataset by selecting others documents containing the keyword Intelligent Transportation Systems.

The presented analysis provides a complete view of the conceptual structure of the ITS research field, giving us the ability to uncover the different topics researched by the ITS community from 1992 to 2011.

We have detected six different main thematic areas: i) VEHICLE-AND-ROAD-TRACKING which evolves from topics related with vehicle surveillance, traffic and incidents detection to the tracking and detection of vehicles, pedestrian, etc. ii) DRIVER-BEHAVIOR-AND-SAFETY related with accident avoidance, conflict resolution and the behavior and safety of the driver, iii) SCENARIOS-SIMULATION associated with the simulations and test of traffic scenarios, iv) TRAFFICFLOW-AND-TRAFFIC-MANAGEMENT related with different aspects of the traffic management using intelligent techniques such as neural networks, v) VEHICLE-CONTROL focused on the research of autonomous vehicles and vi) VEHICLENAVIGATION related with different aspects of traffic networks and route guidance.

Taking into account the detected themes and thematic areas, the following findings can be highlighted:

- The thematic area VEHICLE-AND-ROAD-TRACKING is the most important in all the three criteria used in the analysis. It is a growing research area and presents a good rate of published documents. Furthermore, the research developed under this thematic area captures the attention of the ITS field, as it is illustrated by the citations that it attracts.

- The thematic area VEHICLE-NAVIGATION and VEHICLE-CONTROL start as isolated themes with poor productive and impact rates, but in the last period they get more attention by the community and become two of its most important research topics.

- The thematic area TRAFFIC-FLOW-AND-TRAFFICMANAGEMENT seems a mature research topic and probably in the near future it might evolve following different directions.

- The thematic area DRIVER-BEHAVIOR-AND-SAFETY presents a constant growth.

Interestingly, the thematic areas are covered by the ITS journals in different ways, as it is shown in Table V. We can observe that the journal IEEE Trans. ITS. is the most important journal of the research developed in ITS because it covers all the top ranked and most cited thematic areas. In particular, is the core journal in both thematic areas VEHICLE-AND-ROADTRACKING and VEHICLE-CONTROL. The journal IET Intelligent Transport Systems is centered on DRIVER-BEHAVIORAND-SAFETY and VEHICLE-AND-ROAD-TRACKING. The ITS Journal and Journal of Intelligent Transportation Systems are mainly focused on TRAFFIC-FLOW-AND-TRAFFICMANAGEMENT.

Finally, we should note that the ITS research field is developing at a fast pace. Some of the recent scientific documents are published in conferences or special issues. Although a bibliometric analysis of those documents could be interesting, the amount of documents is not enough to develop a science mapping analysis based solely on them.

\section{ACKNOWLEDGMENTS}

This work has been supported by the Excellence Andalusian Projects TIC-5299 and TIC-5991, and National Project 
TABLE V

JOURNALS PER THEMATIC AREA (DOCUMENTS / CITATIONS).

\begin{tabular}{|c|c|c|c|c|c|c|}
\hline Journal & $\begin{array}{r}\text { VEHICLE AND } \\
\text { ROAD TRACKING }\end{array}$ & $\begin{array}{l}\text { DRIVER BEHAVIOR } \\
\text { AND SAFETY }\end{array}$ & $\begin{array}{r}\text { SCENARIOS } \\
\text { SIMULATION }\end{array}$ & $\begin{array}{r}\text { TRAFFIC FLOW AND } \\
\text { TRAFFIC MNAGEMENT }\end{array}$ & $\begin{array}{l}\text { VEHICLE } \\
\text { CONTROL }\end{array}$ & $\begin{array}{r}\text { VEHICLE } \\
\text { NAVIGATION }\end{array}$ \\
\hline IEEE TRANSACTIONS ON INTELLIGENT TRANSPORTATION SYSTEMS & $\begin{array}{r}\text { ROAD TRACKING } \\
220 / 3111\end{array}$ & $\begin{array}{r}\text { AND SAFETY } \\
115 / 983\end{array}$ & $\begin{array}{r}\text { SIMULATION } \\
54 / 526\end{array}$ & $\begin{array}{r}\text { TRAFFIC MANAGEMENT } \\
124 / 1157\end{array}$ & $\begin{array}{r}\text { CONIROL } \\
3 / 761\end{array}$ & $\begin{array}{r}\text { NAVIGATION } \\
76 / 861\end{array}$ \\
\hline IET INTELLIGENT TRANSPORT SYSTEMS & $41 / 72$ & $60 / 112$ & $13 / 16$ & $30 / 46$ & $6 / 3$ & $20 / 40$ \\
\hline ITS JOURNAL & $12 / 53$ & $3 / 58$ & $2 / 23$ & $21 / 106$ & $1 / 0$ & $4 / 3$ \\
\hline JOURNAL OF INTELLIGENT TRANSPORTATION SYSTEMS & $16 / 58$ & $13 / 62$ & $8 / 21$ & $39 / 170$ & $5 / 68$ & $27 / 119$ \\
\hline Others & $184 / 1310$ & $132 / 721$ & $64 / 490$ & $195 / 1625$ & $50 / 249$ & $75 / 594$ \\
\hline
\end{tabular}

TIN2010-17876.

\section{REFERENCES}

[1] S. Morris and B. Van Der Veer Martens, "Mapping research specialties," Annu. Rev. Inform. Sci. Technol., vol. 42, no. 1, pp. 213-295, 2008.

[2] M. J. Cobo, A. G. López-Herrera, E. Herrera-Viedma, and F. Herrera, "Science mapping software tools: Review, analysis and cooperative study among tools," J. Am. Soc. Inf. Sci. Technol., vol. 62, no. 7, pp. 13821402,2011

[3] F.-Y. Wang, "Building an intellectual highway for its research and development," IEEE Trans. Intell. Transp. Syst., vol. 11, no. 1, pp. 2-3, 2010.

[4] —- "Publication and impact: A bibliographic analysis," IEEE Trans. Intell. Transp. Syst., vol. 11, no. 2, p. 250, 2010.

[5] F.-Y. Wang, A. Broggi, and C. White, "Road to transactions on intelligent transportation systems: A decade's success," IEEE Trans. Intell. Transp. Syst., vol. 10, no. 4, pp. 553-555, 2009.

[6] M. J. Cobo, A. G. López-Herrera, F. Herrera, and E. Herrera-Viedma, "A note on the ITS topic evolution in the period 2000-2009 at T-ITS," IEEE Trans. Intell. Transp. Syst., vol. 13, no. 1, pp. 413-420, 2012.

[7] M. J. Cobo, A. G. López-Herrera, E. Herrera-Viedma, and F. Herrera, "An approach for detecting, quantifying, and visualizing the evolution of a research field: A practical application to the fuzzy sets theory field," J. Informetr., vol. 5, no. 1, pp. 146-166, 2011.

[8] - "Scimat: A new science mapping analysis software tool," J. Am. Soc. Inf. Sci. Technol., vol. 63, no. 8, pp. 1609-1630, 2012.

[9] A. F. J. van Raan, Handbook of Quantitative Science and Technology Research. Springer Netherlands, 2005, ch. Measuring Science, pp. 1950.

[10] E. Garfield, "Scientography: Mapping the tracks of science," Current Contents: Social \& Behavioural Sciences, vol. 7, no. 45, pp. 5-10, 1994.

[11] M. Callon, J. Courtial, and F. Laville, "Co-word analysis as a tool for describing the network of interactions between basic and technological research - the case of polymer chemistry," Scientometrics, vol. 22, no. 1, pp. 155-205, 1991.

[12] M. Callon, J. P. Courtial, W. A. Turner, and S. Bauin, "From translations to problematic networks: An introduction to co-word analysis," Soc. Sci. Inf. Sci. Soc., vol. 22, no. 2, pp. 191-235, 1983.

[13] S. Alonso, F. Cabrerizo, E. Herrera-Viedma, and F. Herrera, "h-index: A review focused in its variants, computation and standardization for different scientific fields," J. Informetr., vol. 3, no. 4, pp. 273-289, 2009.

[14] A. de la Escalera, J. Armingol, J. Pastor, and F. Rodriguez, "Visual sign information extraction and identification by deformable models for intelligent vehicles," IEEE Trans. Intell. Transp. Syst., vol. 5, no. 2, pp. 57-68, 2004.

[15] C. Pai, H. Tyan, Y. Liang, H. Liao, and S. Chen, "Pedestrian detection and tracking at crossroads," Pattern Recognit., vol. 37, no. 5, pp. 1025 1034,2004

[16] I. Alonso, D. Llorca, M. Sotelo, L. Bergasa, P. de Toro, J. Nuevo, M. Ocana, and M. Garrido, "Combination of feature extraction methods for svm pedestrian detection," IEEE Trans. Intell. Transp. Syst., vol. 8, no. 2, pp. 292-307, 2007.

[17] Y. He, H. Wang, and B. Zhang, "Color-based road detection in urban traffic scenes," IEEE Trans. Intell. Transp. Syst., vol. 5, no. 4, pp. 309 318, 2004.

[18] H. Veeraraghavan, O. Masoud, and N. Papanikolopoulos, "Computer vision algorithms for intersection monitoring," IEEE Trans. Intell. Transp. Syst., vol. 4, no. 2, pp. 78-89, 2003.

[19] Z. Kim, "Robust lane detection and tracking in challenging scenarios," IEEE Trans. Intell. Transp. Syst., vol. 9, no. 1, pp. 16-26, 2008.

[20] X. Cao, H. Qiao, and J. Keane, "A low-cost pedestrian-detection system with a single optical camera," IEEE Trans. Intell. Transp. Syst., vol. 9, no. 1 , pp. 58-67, 2008.

[21] M. Trivedi, T. Gandhi, and J. McCall, "Looking-in and looking-out of a vehicle: Computer-vision-based enhanced vehicle safety," IEEE Trans. Intell. Transp. Syst., vol. 8, no. 1, pp. 108-120, 2007.
[22] S. Sivaraman and M. Trivedi, "A general active-learning framework for on-road vehicle recognition and tracking," IEEE Trans. Intell. Transp. Syst., vol. 11, no. 2, pp. 267-276, 2010.

[23] J. Healey and R. Picard, "Detecting stress during real-world driving tasks using physiological sensors," IEEE Trans. Intell. Transp. Syst., vol. 6 , no. 2, pp. 156-166, 2005

[24] N. Agerholm, R. Waagepetersen, N. Tradisauskas, L. Harms, and H. Lahrmann, "Preliminary results from the danish intelligent speed adaptation project pay as you speed," IET Intell. Transp. Syst., vol. 2, no. 2, pp. 143-153, 2008.

[25] I. Spyropoulou, M. Penttinen, M. Karlaftis, T. Vaa, and J. Golias, "Its solutions and accident risks: Prospective and limitations," Transp. Rev., vol. 28, no. 5, pp. 549-572, 2008.

[26] P. Bonsall, "Traveller behavior: Decision-making in an unpredictable world," ITS J., vol. 8, no. 1, pp. 45-60, 2004.

[27] B. Hellinga and L. Fu, "Reducing bias in probe-based arterial link travel time estimates," Transp. Res. Pt. C-Emerg. Technol., vol. 10, no. 4, pp. 257-273, 2002

[28] B. Gokulan and D. Srinivasan, "Distributed geometric fuzzy multiagent urban traffic signal control," IEEE Trans. Intell. Transp. Syst., vol. 11, no. 3, pp. 714-727, 2010.

[29] L. Ng, R. Wessels, D. Do, F. Mannering, and W. Barfield, "Statistical analysis of commercial driver and dispatcher requirements for advanced traveler information systems," Transp. Res. Pt. C-Emerg. Technol., vol. 3, no. 6 , pp. 353-369, 1995

[30] R. Hall, "Route choice and advanced traveler information systems on a capacitated and dynamic network," Transp. Res. Pt. C-Emerg. Technol., vol. 4, no. 5, pp. 289-306, 1996.

[31] K. Rehrl, S. Bruntsch, and H. Mentz, "Assisting multimodal travelers: Design and prototypical implementation of a personal travel companion," IEEE Trans. Intell. Transp. Syst., vol. 8, no. 1, pp. 31-42, 2007.

[32] M. Tan, S. Wong, J. Xu, Z. Guan, and P. Zhang, "An aggregation approach to short-term traffic flow prediction," IEEE Trans. Intell. Transp. Syst., vol. 10, no. 1, pp. 60-69, 2009.

[33] A. Skabardonis and N. Geroliminis, "Real-time monitoring and control on signalized arterials," J. Intell. Transport. Syst., vol. 12, no. 2, pp. $64-74,2008$.

[34] H. Tan and J. Huang, "Dgps-based vehicle-to-vehicle cooperative collision warning: Engineering feasibility viewpoints," IEEE Trans. Intell. Transp. Syst., vol. 7, no. 4, pp. 415-428, 2006.

[35] B. van Arem, C. van Driel, and R. Visser, "The impact of cooperative adaptive cruise control on traffic-flow characteristics," IEEE Trans. Intell. Transp. Syst., vol. 7, no. 4, pp. 429-436, 2006.

[36] J. Naranjo, C. Gonzalez, R. Garcia, and T. de Pedro, "Lane-change fuzzy control in autonomous vehicles for the overtaking maneuver," IEEE Trans. Intell. Transp. Syst., vol. 9, no. 3, pp. 438-450, 2008.

[37] N. Enache, S. Mammar, M. Netto, and B. Lusetti, "Driver steering assistance for lane-departure avoidance based on hybrid automata and composite lyapunov function," IEEE Trans. Intell. Transp. Syst., vol. 11, no. 1, pp. 28-39, 2010.

[38] Z. Peng and R. Huang, "Design and development of interactive trip planning for web-based transit information systems," Transp. Res. Pt. C-Emerg. Technol., vol. 8, no. 1-6, pp. 409-425, 2000.

[39] I. Chabini, "Discrete dynamic shortest path problems in transportation applications - complexity and algorithms with optimal run time," Transp. Res. Record, no. 1645, pp. 170-175, 1998

[40] M. Quddus, R. Noland, and W. Ochieng, "A high accuracy fuzzy logic based map matching algorithm for road transport," J. Intell. Transport. Syst., vol. 10, no. 3, pp. 103-115, 2006.

[41] S. Kim, M. Lewis, and C. White, "Optimal vehicle routing with realtime traffic information," IEEE Trans. Intell. Transp. Syst., vol. 6, no. 2 , pp. $178-188,2005$.

[42] M. Abdel-Aty, A. Pande, A. Das, and W. Knibbe, "Assessing safety on dutch freeways with data from infrastructure-based intelligent transportation systems," Transp. Res. Record, 2008. 